\title{
In situ speciation of uranium in treated acid mine drainage using the diffusion gradients in thin films technique (DGT)
}

\author{
Jorge Henrique Pedrobom a , Carlos Eduardo Eismann a, Amauri A. Menegário a, *, \\ Juliana Aparecida Galhardi ${ }^{a}$, Karen Silva Luko ${ }^{\text {a }}$, Thiago de Araujo Dourado ${ }^{a}$, \\ Chang Hung Kiang ${ }^{b}$ \\ ${ }^{a}$ Centro de Estudos Ambientais - CEA, UNESP - Univ Estadual Paulista, Avenida 24-A, 1515, CEP 13506-900, Rio Claro, SP, Brazil \\ ${ }^{\mathrm{b}}$ Laboratório de Estudos de Bacias - LEBAC, Instituto de Geociências e Ciências Exatas - IGCE, UNESP - Univ Estadual Paulista, Avenida 24-A, 1515, CEP \\ 13506-900, Rio Claro, SP, Brazil
}

\section{H I G H L I G H T S}

- In situ U speciation was performed by using multiple DGT devices.

- Analyses were performed in a $U$ mining area in Brazil.

- Total, cationic and anionic species were sampled by using three different ligands.

- Comparison of in situ and in lab deployments indicates sample modifications.

- Accurate measurements of U speciation must be performed in situ.

\section{A R T I C L E I N F O}

\section{Article history:}

Received 6 July 2016

Received in revised form

4 November 2016

Accepted 15 November 2016

Available online 20 November 2016

Handling Editor: Martine Leermakers

\section{Keywords:}

Uranium

Speciation

In situ

Treated acid mine drainage

Multiple DGT devices

\section{G R A P H I C A L A B S T R A C T}

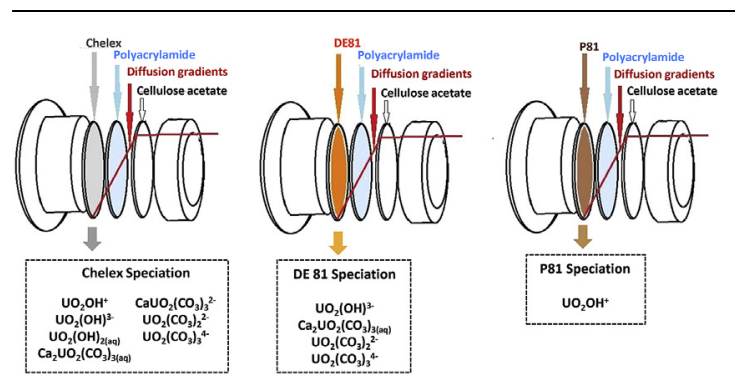

\begin{abstract}
A B S T R A C T
The exchange membranes P81 and DE81 and Chelex-100 resin were used to perform in situ speciation of uranium in treated acid mine drainage at the Osamu Utsumi mining site, Poços de Caldas city, Southeast Brazil. To investigate possible chemical modifications in the samples during analysis, the three ligands were deployed in situ and in a laboratory (in lab). The results obtained in situ were also compared to a speciation performed using Visual MINTEQ software. Chelex-100 retained total labile $U$ for a period of up to $48 \mathrm{~h}$. The labile $\mathrm{U}$ fraction determined by Chelex 100 ranged from $107 \pm 6 \%$ to $147 \pm 44 \%$ in situ and from $115 \pm 22 \%$ to $191 \pm 5 \%$ in lab. DE81 retained anionic $\mathrm{U}$ species up to $8 \mathrm{~h}$, with labile fractions ranging from $37 \pm 2 \%$ to $76 \pm 3 \%$ in situ and $34 \pm 12 \%$ to $180 \pm 17 \%$ in lab. P81 exhibited a lower efficiency in retaining $U$ species, with concentrations ranging from $6 \pm 2 \%$ to $19 \pm 2 \%$ in situ and $3 \pm 2 \%$ to $18 \pm 2 \%$ in lab. The speciation obtained from MINTEQ suggests that the major $\mathrm{U}$ species were $\mathrm{UO}_{2} \mathrm{OH}^{+}, \mathrm{UO}_{2}(\mathrm{OH})^{3-}$, $\mathrm{UO}_{2}(\mathrm{OH})_{2(\mathrm{aq})}, \mathrm{Ca}_{2} \mathrm{UO}_{2}\left(\mathrm{CO}_{3}\right)_{3(\mathrm{aq})}, \mathrm{CaUO}_{2}\left(\mathrm{CO}_{3}\right)_{3}^{2-}, \mathrm{UO}_{2}\left(\mathrm{CO}_{3}\right)_{2}^{2-}$, and $\mathrm{UO}_{2}\left(\mathrm{CO}_{3}\right)_{3}^{4-}$. This result is in accordance with the results obtained in situ. Differences concerning speciation and the total and soluble $\mathrm{U}$ concentrations were observed between the deployments performed in situ and in the laboratory, indicating that $\mathrm{U}$ speciation must be performed in situ.
\end{abstract}

๑) 2016 Elsevier Ltd. All rights reserved.

\footnotetext{
* Corresponding author.

E-mail address: amenega@rc.unesp.br (A.A. Menegário).
}

\section{Introduction}

Uranium occurs as a natural element in the earth's crust. It is commonly found at low concentrations in aquatic environments. 
Anthropogenic activities, such as nuclear energy generation, the use of nuclear weapons and accidental release of radioactive material, are capable of increasing the amount of this element in water systems (Vandenhove et al., 2010). In mining sites, the occurrence of acid mine drainage (AMD) is frequent and can increase the contamination risks for natural waters (Al-Hashimi, 1996). This phenomenon is generated when sulphide minerals (present in the tailings pile and in the reject dumps in mining areas) are oxidized in the presence of water and oxygen (Al-Hashimi, 1996). The acid effluent can increase the contaminants content in the environment when it is not properly controlled (Fernandes and Franklin, 2001). It can accelerate and promote toxic element leaching and transport into surface water and groundwater (Al-Hashimi, 1996).

The most commonly used method for removing metals from acid effluent involves the active addition of a neutralizing agent (Johnson and Hallberg, 2005). Although the U total concentration and isotopic composition are responsible for the radiological impact of this element, its chemical speciation is associated with its toxicity and bioavailability (Francis, 1990). The speciation is also a reliable tool to evaluate the treatment efficiency, to predict the bioavailability and to provide information on the species being deposited in the environment (Strosnider et al., 2011). In this context, the development of analytical techniques that allow $U$ and its different species in treated AMD samples to be determined is essential to the study of $U$ behaviour under different environmental conditions.

The task of sampling and transportation of material to the laboratory can be critical due to potential contamination sources and the chemical changes during the collecting and storing processes. This can lead to differences and errors in the chemical species distribution between the natural environment and laboratory conditions (Davison and Zhang, 1994). In situ approaches can overcome these possible errors, exhibiting satisfactory results concerning the real chemical conditions of the studied system (Davison and Zhang, 1994).

Diffusive gradients in thin films (DGT) are passive samplers that are used for the determination of the labile fraction and the chemical speciation of metals in natural water (Zhang and Davison, 1995; Zhang and Davison, 2000). This technique is based on Fick's first law of diffusion, in which the concentration of the analytes is determined from the mass retained in the binding layer after diffusion through a hydrogel (Davison and Zhang, 1994; Zhang and Davison, 1999). Discrimination of the different chemical species is possible according to their distinct diffusion properties. Free metals, inorganic complexes that are easy to dissociate and some organic complexes are mainly sampled by DGT devices (Davison and Zhang, 1994, 2012).

The DGT technique has been widely used in studies focusing on metal speciation in natural water. The main advantages of DGT are associated with its in situ sampling, preconcentration of analyte, measurements with integrated time and a low potential to contaminate samples. Conventional DGT devices employ Chelex100 resin as a binding agent. Theoretically, Chelex 100 resin has the capacity to retain $364 \mathrm{nmol}$ of $U$ and is composed of a styrene divinylbenzene copolymer containing paired iminodiacetate functional groups (Li et al., 2006). The replacement of Chelex-100 by other binding agents with different chemical characteristics can lead to differential sampling and different information about a species' chemistry (Davison and Zhang, 1994, 2012). For example, Li et al. (2006) determined the $U$ concentration in alkaline water by using the anionic exchange membrane DE81 as a binding phase. The authors reported that this binder phase consists of the replacement of cellulose polymers by diethylaminoethyl functional groups that can retain up to $625 \mathrm{nmol}$ of $U$, theoretically. In this condition, DE81 has proved to be useful to retain anionic U species (complexed with carbonate) (Li et al., 2006). Dowex and SpheronOxin resins have also been proposed to retain similar $U$ species (Li et al., 2007), (Gregusova and Docekal, 2011).

Turner et al. (2012) evaluated the performance of DGT devices for $\mathrm{U}$ determination, assembled with Metsorb or $\mathrm{MnO}_{2}$ as binding phases. $\mathrm{MnO}_{2}$ was effective for determining the $\mathrm{U}$ concentration in seawater, while Metsorb was effective for freshwater analysis (Turner et al., 2012). Metsorb was also successfully used for U determination at Rio Comora in Australia (Hutchins et al., 2012) and in alkaline river water in the United Kingdom (Turner et al., 2014). A ligand with a high partition coefficient for actinides (Diphonix) was recently tested for $U$ determination using DGT. Diphonix resin showed a low influence of the main variables of the DGT technique (Turner et al., 2015; Drozdzak et al., 2015). The P81 membrane is a cationic exchange membrane containing cellulose phosphate functional groups (exchange capacity $=18 \mu \mathrm{Eq} \mathrm{\textrm {cm } ^ { - 2 }}$ ) that was previously used in DGT as binding layer for retaining $\mathrm{Hg}$ (II) in river water (Colaço et al., 2014). Until now, the P81 membrane has not been used as a binder layer for determination of $U$ species. Although the DGT technique has been successfully applied for the determination of more than 55 different elements, including $\mathrm{U}$ (Garmo et al., 2003), the use of only one type of device cannot provide accurate information about the different chemical species present in the system. The ionic strength and $\mathrm{pH}$ of potential concomitant interferents (bicarbonate, phosphate and sulphate) are the main variables of the DGT technique that have been widely studied regarding the speciation of $U$ (Turner et al., 2012). Approaches using multiple devices with different binding phases provide more complete information about the speciation and distribution of the chemical species of an element in an aquatic system. This approach was successfully used to determine the speciation of Mn in treated AMD (Oliveira et al., 2013). Furthermore, Drozdzak et al. (2016) investigated the fractionation and speciation of $U$ around a mining site in France. An approach using multiple DGT devices (Diphonix, Metsorb and Chelex 100) combined with ultrafiltration was applied, and the results were promising.

This research aimed to perform in situ $U$ speciation in treated AMD utilizing an approach based on multiple DGT devices at the uranium mining area in Poços de Caldas city, Minas Gerais State, Southeast Brazil, where AMD generation was previously studied (Veiga et al., 2003). Devices containing Chelex-100 as well as DE81 and P81 binding phases were tested to selectively sample the U species (cationic, anionic and neutral) present in treated AMD. This study also aimed to evaluate potential alterations of chemical species in samples collected in the field and those taken in the laboratory (in lab).

\section{Material and methods}

\subsection{Equipment and accessories}

Determination of the $U$ concentration was performed with an inductively coupled plasma mass spectrometer (ICP-MS) (Thermo Scientific, model X series II, Bremen Germany) equipped with an impact bead spray chamber and a MiraMist nebulizer. The isotope measured was ${ }^{238} \mathrm{U}$. The spectrometer was operated under the following conditions: forward power $=1480 \mathrm{~W}$; plasma gas flow $=13 \mathrm{~L} \mathrm{~min}^{-1}$; auxiliary gas flow $=0.70 \mathrm{~L} \mathrm{~min}^{-1}$; nebulizer gas flow $=0.79 \mathrm{~L} \mathrm{~min}^{-1}$; and sample flow $=1 \mathrm{~mL} \mathrm{~min}^{-1}$

The determinations of $\mathrm{Ca}$ and $\mathrm{Mg}$ were performed by using an inductively coupled plasma optic emission spectrometer (ICP-OES) (Thermo Scientific, model iCAP 6000 series, Bremen, Germany) equipped with a cyclonic chamber and a V-groove nebulizer. Ca and $\mathrm{Mg}$ were measured at 184.006 and $279.553 \mathrm{~nm}$, respectively. The 
spectrometer was operated under the following conditions: forward power $=1150 \mathrm{~W}$; plasma gas flow $=10 \mathrm{~L} \mathrm{~min}^{-1}$; auxiliary gas flow $=0.5 \mathrm{~L} \mathrm{~min}^{-1}$; nebulizer gas flow $=0.7 \mathrm{~L} \mathrm{~min}^{-1}$; and sample flow $=3.0 \mathrm{~mL} \mathrm{~min}^{-1}$

Determination of the concentration of major anions and cations (except $\mathrm{Ca}$ and $\mathrm{Mg}$ ) was performed using an Ionic Chromatograph (Metrohm, Brazil). A multiparameter probe was used to measure $\mathrm{pH}$, conductivity and temperature (Horiba U50, Fukuoka, Japan).

Polypropylene DGT devices were purchased from DGT Research Ltd., Lancaster, UK. The binding agents used in the DGT experiments were Chelex-100 (DGT Research, Lancaster, UK) and the cellulose membranes P81 and DE81 (Whatmann ${ }^{\mathrm{TM}}$, Maidastone, UK). A polyacrylamide-agarose hydrogel (DGT Research, Lancaster, UK) was used as the diffusive agent and a cellulose acetate membrane was used as the filter (Sartorius Biotech, Goettingen, Germany).

\subsection{Reagents and solutions}

$\mathrm{U}$ standard solutions were diluted from a $10 \mathrm{mg} \mathrm{L}^{-1}$ stock solution (SpecSol, Quimlab ${ }^{\circledR}$, São Paulo, Brazil) in $0.5 \mathrm{M} \mathrm{HNO}_{3} \cdot{ }^{209} \mathrm{Bi}$ and ${ }^{165} \mathrm{Ho}$ were used as internal standards (by using interpolation mode). Internal standards were obtained from a multi-element solution containing $10 \mu \mathrm{g} \mathrm{L}{ }^{-1}$ of ${ }^{6} \mathrm{Li}^{45} \mathrm{Sc},{ }^{89} \mathrm{Y},{ }^{115} \mathrm{In},{ }^{159} \mathrm{~Tb},{ }^{209} \mathrm{Bi}$ and ${ }^{165} \mathrm{Ho}$. The $\mathrm{HNO}_{3}$ used in the experiments was purified by subboiling distillation from analytical grade reagent. Purified water $(18 \mathrm{M} \Omega \mathrm{cm}$ ) was used throughout (milli-Q Millipore, Massachusetts, USA).

\subsection{Preparation of the discs}

Chelex-100 discs ( $2.5 \mathrm{~cm}$ diameter and $0.4 \mathrm{~mm}$ thickness) were cut from commercially available sheets and stored in a $0.05 \mathrm{M} \mathrm{NaCl}$ solution. DE81, P81 and the cellulose acetate filter discs were decontaminated by immersion in $10 \%(\mathrm{v} / \mathrm{v}) \mathrm{HNO}_{3}$ for $24 \mathrm{~h}$. Afterwards, the discs were stored in ultrapure water. Polyacrylamideagarose hydrogel discs (2.5 $\mathrm{cm}$ diameter and $0.8 \mathrm{~mm}$ thickness) were cut from commercially available sheets $(13 \mathrm{~cm} \times 13 \mathrm{~cm})$ and stored in a $0.05 \mathrm{M} \mathrm{NaCl}$ solution.

\subsection{Assembling of the devices}

The DGT devices were assembled according to the process described previously by Davison and Zhang (1994). The binding layer (Chelex-100, DE81 or P81) was settled directly on the piston, followed by the polyacrylamide-agarose gel layer and finally an acetate cellulose filtering layer. A polypropylene cap with a $20-\mathrm{mm}$ diameter window was then added, closing the system.

\subsection{Elution and calculation}

Elution of the analyte was conducted according to the procedure previously described by Li et al. (2007). The same procedure was used for both ligands and consisted of an immersion of the ligands in $2.0 \mathrm{~mL}$ of $2 \mathrm{M} \mathrm{HNO}_{3}$ for a $24 \mathrm{~h}$ period. After this process, the discs were removed and discarded. Determination of the $U$ concentration was performed by ICP-MS. Elution factors of 0.87 and 0.67 were assumed for DE81 and Chelex-100, respectively, as described by Li et al. (2006). An elution factor of 1.00 was assumed for P81 (Oliveira et al., 2013.)

The mass (M) of $U$ accumulated by DGT was calculated based on Eq. (1)
$M=\frac{C_{e} \cdot\left(V_{e}+V_{L}\right)}{f_{R}}$

where $C_{e}$ is the $U$ concentration in the eluate, $V_{L}$ is the volume of the binding agent, $\mathrm{V}_{\mathrm{e}}$ is the volume of the acid used in the elution process and $f_{R}$ is the elution factor.

The $U$ concentration in the system $\left(C_{b}\right)$ was calculated using Eq. (2)

$C_{b}=\frac{M \cdot \Delta g}{D \cdot t \cdot A}$

where $\Delta \mathrm{g}$ is the diffusive layer thickness $(0.093 \mathrm{~cm}), \mathrm{M}$ is the $\mathrm{U}$ mass accumulated in the ligand, $D$ is the diffusion coefficient of $U$ in the polyacrylamide-agarose hydrogel, $\mathrm{t}$ is the immersion time and $A$ is the diffusion window area $\left(3.14 \mathrm{~cm}^{2}\right)$.

The D values reported by Hutchins et al., 2012 (as a function of $\mathrm{pH}$ ) were used for calculation. These values are presented in the supplementary material (Table S1).

\subsection{Samples and sampling sites}

The sampling sites selected are located at the Osamu Utsumi mining area, in the city of Poços de Caldas, Minas Gerais State, Southeast Brazil. U extraction occurred from 1982 to 1995 (Souza et al., 2013), which gave rise to two principal sources of environmental contaminants: waste rock dump and tailings pile. Currently, the mine is disabled. The ADM phenomenon occurs in the area, generating approximately $300 \mathrm{~m}^{3} \mathrm{~h}^{-1}$ of acid effluents. The mine has an active maintenance system whose focus is treating AMD that is mainly generated in waste dumps and the tailings pile. Chemical treatment of AMD in the area involved adding $\mathrm{CaO}$ to increase its $\mathrm{pH}$ (initially approximately 3 ) to values near 10 (Santos and Ladeira, 2009). The effluent generated in the yellowcake factory is also contaminated with $U$, Th and other radionuclides and is treated by $\mathrm{CaO}$ and/or $\mathrm{BaCl}_{2}$ addition (Fernandes and Franklin, 2001).

Effluent samples were collected from 4 different sites at the Osamu Utsumi mine. The 022-E sampling site is located just after treatment of the effluent (with $\mathrm{CaO}$ and $\mathrm{BaCl}_{2}$ addition), while the 025 -E sampling site is located in a decantation pound. Site 041 is located after decantation subsequent only $\mathrm{CaO}$ addition, and site 014 is located after the dilution process, posterior to site 041 (right before it enters the environment) (Fig. 1). For preliminary tests, $5 \mathrm{~L}$ of each sample was collected using polyethylene flasks that were previously decontaminated in the laboratory with nitric acid and washed three times with each sample in the field. During transport, the water samples were kept at room temperature, while the DGT devices were refrigerated until they were dismounted. Samples were analysed $24 \mathrm{~h}$ after collection.

\subsection{Preliminary studies (deployment curves)}

Preliminary studies were performed to evaluate the applicability of the DGT technique applied to the proposed samples. A volume of $5 \mathrm{~L}$ of each effluent sample collected from the sampling sites described above was used for the immersion of 18 DGT devices (6 with Chelex-100, 6 with P81 and 6 with DE81). The devices were removed after $2,4,6,12,24$ and $48 \mathrm{~h}$. During immersion, samples were continuously stirred and the $\mathrm{pH}$ and temperature were monitored. After each removal, the devices were disassembled and the binding phase was removed and submitted to the elution process. Quantification of U was performed by ICP-MS. 


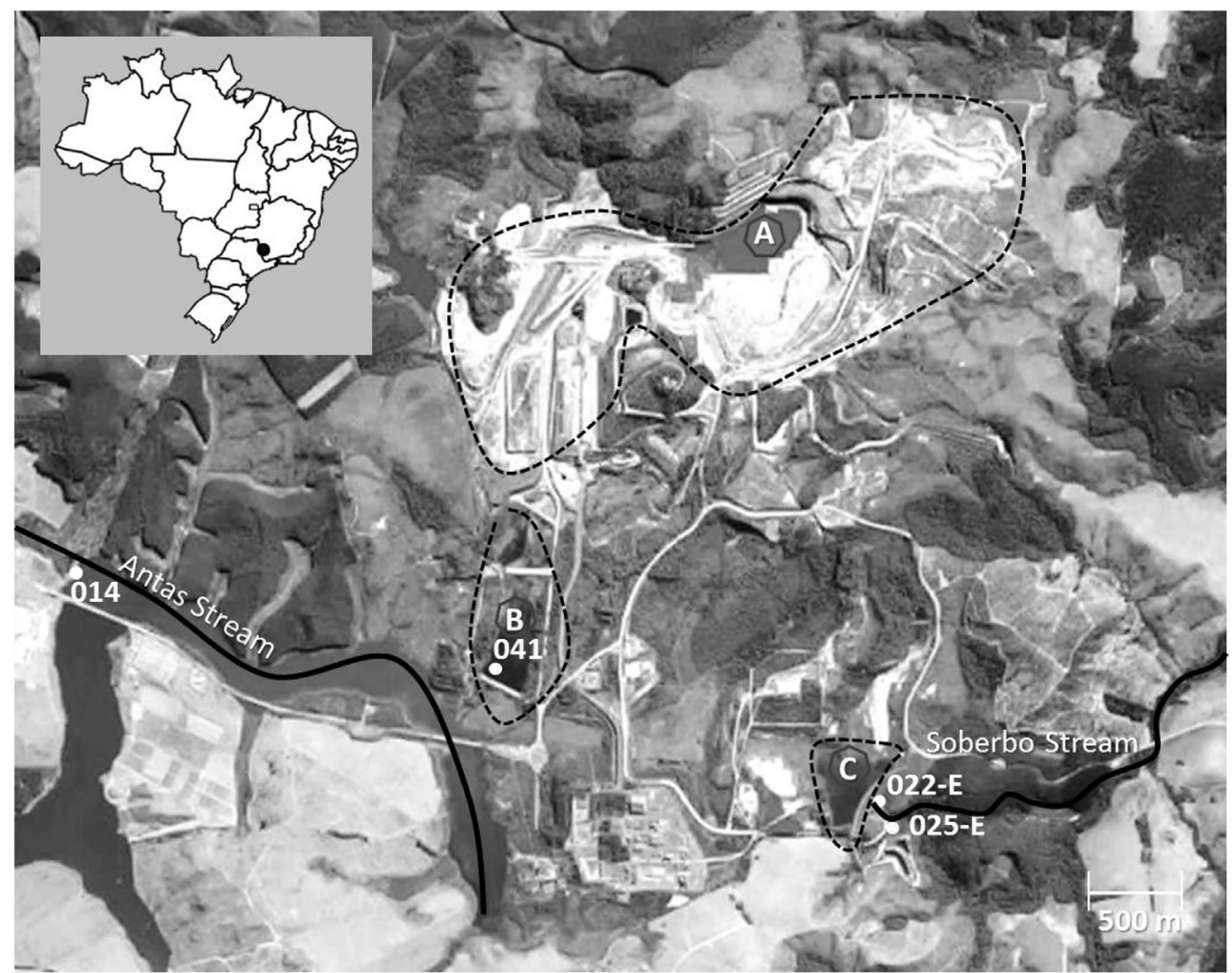

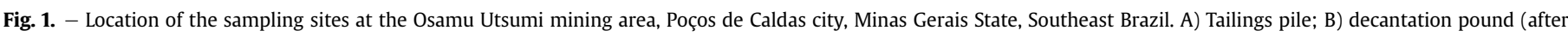

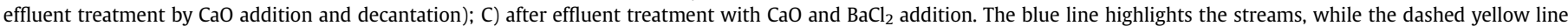
delineates areas $\mathrm{A}, \mathrm{B}$ and $\mathrm{C}$.

\subsection{Deployments (in situ and in lab)}

\subsubsection{In situ}

In a hexagonal bracket, 6 devices ( 2 of each ligand, Chelex-100, DE81 and P81) were displaced. The bracket was placed at a $1 \mathrm{~m}$ depth at each of the four sites (022-E, 025-E, 041 and 014). An optimal sampling time of $4 \mathrm{~h}$ was defined according to preliminary studies. The devices were removed and taken to the laboratory after this sampling time, and the binding phase was submitted to the elution process described in 2.5. Quantification of $U$ was performed by ICP-MS.

\subsubsection{In lab}

A volume of $5 \mathrm{~L}$ of each sample was collected during the in situ experiment and taken to the laboratory. Deployments were conducted between 12 and $24 \mathrm{~h}$ after field sampling. The DGT devices were placed in a bracket as in the in situ procedure. Stirring was maintained during the $4 \mathrm{~h}$ of deployment. After this period, the devices were disassembled and the binding phase submitted to the elution process described in 2.5. Quantification of $U$ was performed by ICP-MS. The results of the in lab experiments were compared to the in situ results.

\section{Results and discussion}

\subsection{Preliminary studies}

The efficiency of the DGT devices for $U$ retention in the samples collected from the sampling sites was evaluated. The soluble $U$ average concentrations were determined in the laboratory for samples 022-E, 025-E, 041 and 014 were 0.56, 2.37, 48.2 and
$1.78 \mu \mathrm{g} \mathrm{L}^{-1}$, respectively.

In Brazil, the standards for surface water quality are described in CONAMA Resolution No. 357 (CONAMA, 2005), which classifies water by biological, chemical and physico-chemical parameters and also according to the intended use of each water system. According to this Resolution, water classified into Class II (as it occurs in the Antas and Soberbo River) can be used for human consumption after simplified treatment, protection of aquatic communities, recreation activities, aquaculture and irrigation. The maximum level (ML) for uranium in this case is $0.02 \mathrm{mg} \mathrm{L}^{-1}$. Thus, samples collected from the Antas River meet the requirements of this resolution. The World Health Organization (WHO) recognized a guideline value of $0.015 \mathrm{mg} \mathrm{L}^{-1}$ for naturally occurring uranium, which is of health significance in drinking water (WHO, 2006). According to the EPA, the maximum contaminant level (MCL) for uranium, i.e., the maximum permissible level of this element in water used for human consumption, is $30 \mu \mathrm{g} \mathrm{L} \mathrm{L}^{-1}$ (EPA, 2015). The results indicate that only sample 041 exhibited a uranium content higher than the EPA and WHO guidelines.

Drozdzak et al. (2016) found average U contents (by using DGT devices) in a uranium mining area located in western France of $488.03 \mu \mathrm{g} \mathrm{L}^{-1}$ (for former open pit water) and $24.47 \mu \mathrm{g} \mathrm{L}^{-1}$ (for discharge water). These values were higher the than soluble $U$ average concentrations found at Caldas, southern Brazil.

The average pHs during laboratory deployments were $10.22 \pm 1.2,6.6 \pm 0.2,8.1 \pm 0.7$ and $5.7 \pm 0.5$ for samples $022-\mathrm{E}, 025-$ E, 041 and 014, respectively. Fig. 2(a-d) exhibits the mass accumulation versus exposure time of the three binding phases in all samples.

A significant linear correlation (characterized by $\mathrm{R}^{2}>0.85$ ) between the uptake of $U$ and time was obtained up to $48 \mathrm{~h}$ for all 

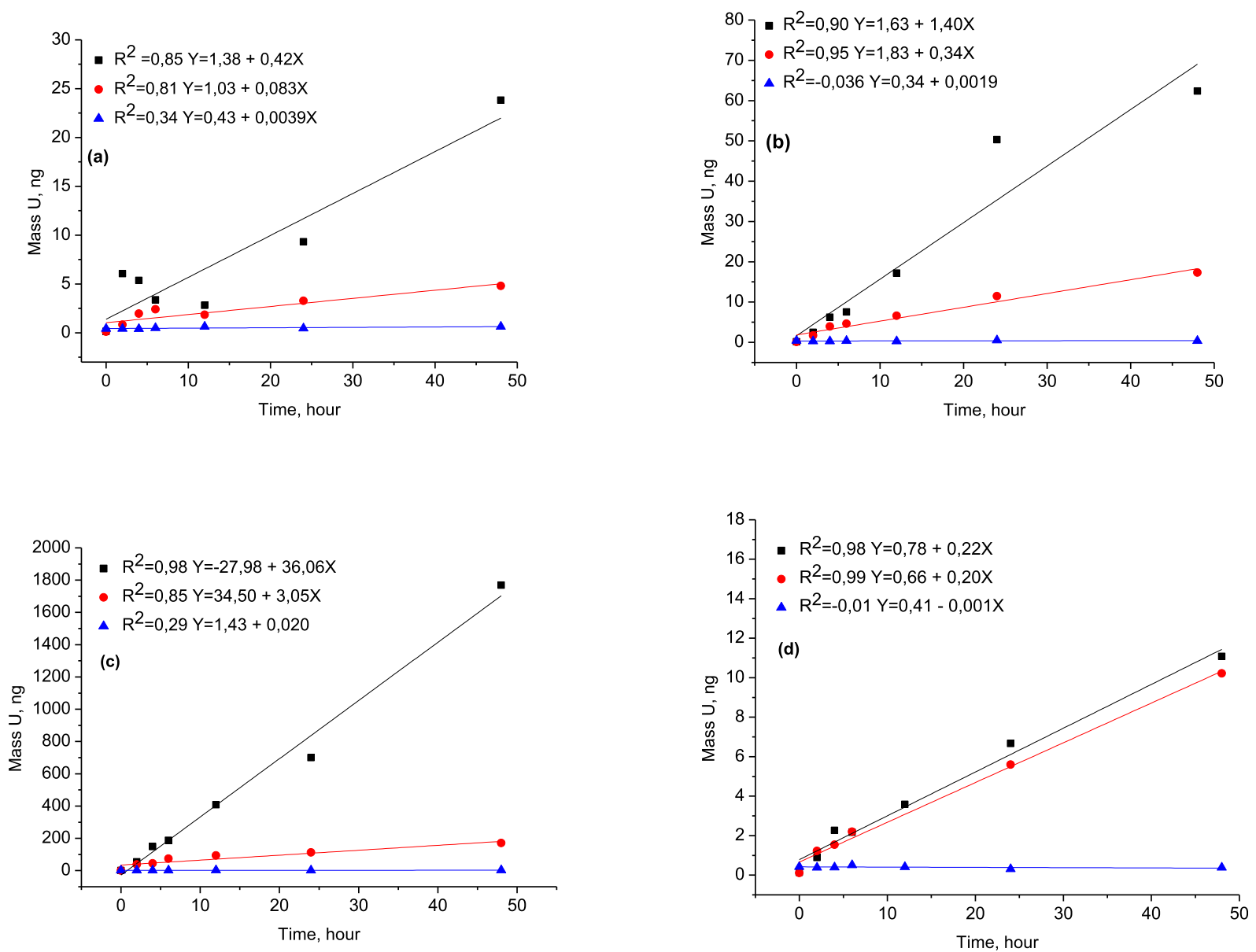

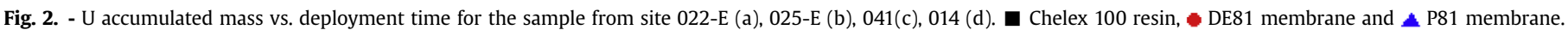

samples when using Chelex-100 as a binding phase (Fig. 2a-d). From these data, the average labile $U$ concentration measured by DGT was $0.78 \pm 0.27,3.00 \pm 0.28,60.85 \pm 7.86$ and $0.81 \pm 0.28 \mu \mathrm{g} \mathrm{L}^{-1}$ for the samples 022-E, 025-E, 041 and 014 , respectively. These values represent $139 \pm 47 \%, 126 \pm 12 \%, 126 \pm 16 \%$ and $45 \pm 15 \%$ of the soluble concentration determined in the samples. It is difficult to explain the low recovery in sample 014 ( $45 \pm 15 \%)$, but it may be caused by a change of the $U$ species during deployment. This change is observable in this sample, as the proportion of negative chemical species $\left(\mathrm{CaUO}_{2}\left(\mathrm{CO}_{3}\right)_{3}^{2-}\right)$ is $61.4 \%$ of neutral species $\left(\mathrm{Ca}_{2} \mathrm{UO}_{2}\left(\mathrm{CO}_{3}\right)_{3(\mathrm{aq})}\right)$. In comparison, this relationship for sample 025 -E is $15.6 \%$. The high relative standard deviation found for sample $022 \mathrm{E}$ is probably due to the low level of $U$ found in this sample. For the 022-E, 025-E and 041 samples, the mass uptake of $U$ by DE81 increased rapidly until $8 \mathrm{~h}$. Then, a plateau of saturation was observed (Fig. 2(a)-(c)). The decrease in $U$ uptake is probably associated with the high $\mathrm{SO}_{4}^{-2}$ concentrations (>400 $\mathrm{mg} \mathrm{L}^{-1}$ ) in these samples. For further experiments, the maximum deployment time when using DE81 as the binding phase was set at $8 \mathrm{~h}$. The labile uranium concentration was determined as $0.80 \pm 0.08,1.92 \pm 0.19,28.51 \pm 10.43$ and $0.80 \pm 0.35 \mu \mathrm{g} \mathrm{L}^{-1}$ for the 022-E, 025-E, 041 and 014 samples, respectively. These values represent $142 \pm 13 \%, 81 \pm 8 \%, 59 \pm 21 \%$ and $45 \pm 18 \%$ of the soluble concentration determined for the 022-E, 025-E, 041 and 014 samples, respectively.

The P81 membrane showed no significant linear correlation $\left(\mathrm{R}^{2}<0.46\right)$ in the deployment period for all samples. The speciation models that were previously used for synthetic river water solutions and local river water in Canada (Li et al., 2006), for carbonate loaded solutions of natural water (Gregusova and Docekal, 2011), and for synthetic water (Drozdzak et al., 2015) indicated a very low $(<10 \%)$ or no presence of cationic $U$ species at a $\mathrm{pH}>6$. Thus, it is expected that the P81 membrane was not saturated and that positively charged species were absent from the sample.

A better view (e.g., linear range, plateau) of the plots of Fig. 2 is presented in the supplementary material (Fig. S1a to S4a). Instrumental limit of detection for $U$ was $20 \mathrm{ng} \mathrm{L}^{-1}$. Frequently, the precision of the DGT measurements was characterized by a relative standard deviation that ranged from 5.7 to 6.5 for all ligands $(n=3$, $\left.13 \mu \mathrm{g} \mathrm{L}^{-1}\right)$.

\subsection{Deployments}

\subsection{1. $U$ species and in situ speciation}

Table 1 shows the $\mathrm{pH}$, conductivity, temperature and major cation concentrations measured in the four sampling sites. These values and $U$ concentrations for the respective sites were used as inputs for Visual MINTEQ $\left({ }^{\odot} 2010 \mathrm{KTH}\right.$, Department of Land and Water Resources Engineering, Stockholm, Sweden) to perform U speciation.

The soluble $U$ concentration was smaller than the total U concentration at all sites, as exhibited in Table 3, showing that some amount of $U$ precipitated or associated with particulate material. The concentrations measured when using Chelex-100 indicate that $\mathrm{Ca}_{2} \mathrm{UO}_{2}\left(\mathrm{CO}_{3}\right)_{3(\mathrm{aq})}$ is labile and that negative species were retained by the resin $\left(\mathrm{CaUO}_{2}\left(\mathrm{CO}_{3}\right)_{3}^{2-}\right)$ once retentions from 107 to $147 \%$ were 
Table 1

Temperature, conductivity, $\mathrm{pH}$ and concentration of the major cations and anions in water of the treated acid mine drainage of the Osamu Utsumi mine.

\begin{tabular}{|c|c|c|c|c|}
\hline & \multicolumn{4}{|l|}{ Sites } \\
\hline & 014 & 041 & 022-E & 025-E \\
\hline${ }^{\mathrm{a}} \mathrm{pH}$ & 6.91 & 8.48 & 7.45 & 7.19 \\
\hline${ }^{\mathrm{a} C}$ Conductivity, $\mathrm{mS} \mathrm{cm}{ }^{-1}$ & 0.182 & 1.168 & 0.921 & 0.904 \\
\hline${ }^{\mathrm{a}} \mathrm{T},{ }^{\circ} \mathrm{C}$ & 25 & 25 & 25 & 25 \\
\hline $\mathrm{Ca}, \mathrm{mgL}^{-1}$ & 32 & 212 & 180 & 202 \\
\hline $\mathrm{K}, \mathrm{mgL}^{-1}$ & 2.6 & 5.9 & 6.7 & 7.0 \\
\hline $\mathrm{Mg}, \mathrm{mgL}^{-1}$ & 0.5 & 0.4 & 0.9 & 1.2 \\
\hline $\mathrm{Na}, \mathrm{mgL}^{-1}$ & 1 & 2.1 & 4.0 & 4.5 \\
\hline $\mathrm{Li}, \mathrm{mgL}^{-1}$ & $<0.01$ & $<0.010$ & $<0.010$ & $<0.010$ \\
\hline $\mathrm{NH}_{4}, \mathrm{mgL}^{-1}$ & $<0.05$ & $<0.050$ & $<0.050$ & $<0.050$ \\
\hline $\mathrm{SO}_{4}^{2-}, \mathrm{mgL}^{-1}$ & 58.6 & 601 & 469 & 458 \\
\hline $\mathrm{Cl}^{-}, \mathrm{mgL}^{-1}$ & 1.8 & 1.1 & 4.3 & 5.2 \\
\hline $\mathrm{F}^{-}, \mathrm{mgL}^{-1}$ & 2.6 & 11.0 & 4.1 & 3.7 \\
\hline $\mathrm{PO}_{4}^{-}, \mathrm{mgL}^{-1}$ & $<0.04$ & $<0.04$ & $<0.04$ & $<0.04$ \\
\hline $\mathrm{NO}_{2}^{-}, \mathrm{mgL}^{-1}$ & $<0.02$ & $<0.02$ & $<0.02$ & $<0.02$ \\
\hline $\mathrm{NO}_{3}^{-}, \mathrm{mgL}^{-1}$ & 0.4 & $<0.04$ & $<0.04$ & $<0.04$ \\
\hline $\mathrm{SO}_{4}^{2-}, \mathrm{mgL}^{-1}$ & 59 & 601 & 469 & 458 \\
\hline $\mathrm{C}_{2} \mathrm{O}_{4}^{2-}, \mathrm{mgL}^{-1}$ & $<0.10$ & $<0.10$ & $<0.10$ & $<0.10$ \\
\hline $\mathrm{C}_{2} \mathrm{H}_{3} \mathrm{O}_{2}^{-}, \mathrm{mgL}^{-1}$ & $<0.10$ & $<0.10$ & $<0.10$ & $<0.10$ \\
\hline $\mathrm{Br}^{-}, \mathrm{mgL}^{-1}$ & $<0.03$ & $<0.03$ & $<0.03$ & $<0.03$ \\
\hline $\mathrm{HCO}_{3}^{-}, \mathrm{mgL}^{-1}$ & 11.2 & 19.9 & 18.3 & 14.9 \\
\hline $\mathrm{CO}_{3}^{2-}, \mathrm{mgL}^{-1}$ & - & 13.4 & - & - \\
\hline $\mathrm{U}, \mu \mathrm{gL}^{-1}$ & 3.73 & 14.15 & 3.14 & 4.55 \\
\hline
\end{tabular}

a Measurements during deployments of DGT in situ.

verified (Table 2). Li et al. (2006) suggests that the negative charges present in the carboxylic groups of Chelex-100 can inhibit the retention of $U$ anionic species by electrostatic repulsion at a neutral or alkaline $\mathrm{pH}$. However, this suggestion was not verified in this study.

The $U$ fraction measured when using the DE81 membrane represented $52.1 \pm 0.2 \%, 49.8 \pm 0.4 \%, 36.8 \pm 2.4 \%$ and $76.4 \pm 3.1 \%$ of the soluble fraction $t$ the $022-\mathrm{E}, 025-\mathrm{E}, 041$ and 014 sites, respectively, indicating that some of the $\mathrm{U}$ is in anionic form. The anionic species given by the software Visual MINTEQ were $\mathrm{UO}_{2}(\mathrm{OH})^{3-}$, $\mathrm{CaUO}_{2}\left(\mathrm{CO}_{3}\right)_{3}^{2-}, \mathrm{UO}_{2}\left(\mathrm{CO}_{3}\right)_{2}^{2-}$ and $\mathrm{UO}_{2}\left(\mathrm{CO}_{3}\right)_{3}^{4-}$ (Table 2$)$. The values obtained for the DE81 membrane were in reasonable agreement with the values estimated by Visual MINTEQ. However, quantitative comparison shows that the data obtained when using DE81 were overestimated compared with software speciation, which is a consequence of the $\mathrm{Ca}_{2} \mathrm{UO}_{2}\left(\mathrm{CO}_{3}\right)$ species lability (Turner et al., 2012). Additionally, the Visual MINTEQ software might be unable to model the system accurately. The file vminteq30 |thermo.vdb thermodynamic database was used.

The U concentration retained by P81 was $0.44 \mu \mathrm{g} \mathrm{L}^{-1}$ in $022-\mathrm{E}$ sample and $0.42 \mu \mathrm{g} \mathrm{L}^{-1}$ in 025 -E sample. These values represent $19 \%$ and $10 \%$ of the soluble fraction. The cationic labile fraction in sites 041 and 014 was $5.6 \%$ and 6\%, respectively (Table 2). The presence of cationic $U$ species was not expected by the preliminary study or by the software speciation $(<0.02 \%$ were expected to be cationic species at these sites). The difference between the software speciation and cationic $U$ fraction determined by $P 81$ might be due to the complexity of the site (Table 2). Although useful information about the speciation of a system is given by the software, it cannot overcome or even consider all of the variables present in a natural complex system.

\subsection{In situ $X$ in lab speciation}

Table 3 shows the results for the total, soluble and labile

Table 2

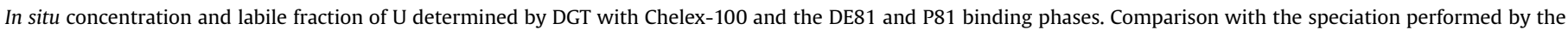
software Visual MINTEQ.

\begin{tabular}{|c|c|c|c|c|c|}
\hline & & \multicolumn{4}{|l|}{ Site } \\
\hline & & 014 & 041 & 022-E & 025-E \\
\hline \multirow[t]{2}{*}{ Chelex-100 } & $\mu \mathrm{g} \mathrm{L}^{-1}$ & $4.23 \pm 1.26$ & $14.00 \pm 0.85$ & $2.91 \pm 0.23$ & $5.50 \pm 0.04$ \\
\hline & $\%$ & $147 \pm 44$ & $107 \pm 6$ & $130 \pm 10$ & $123 \pm 1$ \\
\hline \multirow[t]{2}{*}{ DE81 } & $\mu \mathrm{g} \mathrm{L}^{-1}$ & $2.20 \pm 0.09$ & $4.79 \pm 0.31$ & $1.17 \pm 0.01$ & $2.21 \pm 0.02$ \\
\hline & $\%$ & $76 \pm 3$ & $37 \pm 2$ & $52 \pm 1$ & $50 \pm 1$ \\
\hline \multirow[t]{2}{*}{ P81 } & $\mu \mathrm{g} \mathrm{L}^{-1}$ & $0.18 \pm 0.06$ & $0.73 \pm 0.04$ & $0.42 \pm 0.04$ & $0.44 \pm 0.12$ \\
\hline & $\%$ & $6 \pm 2$ & $6 \pm 1$ & $19 \pm 2$ & $10 \pm 3$ \\
\hline MINTEQ & $\mathrm{UO}_{2} \mathrm{OH}^{+} \%$ & - & - & - & 0.02 \\
\hline \multirow[t]{6}{*}{ Speciation } & $\mathrm{UO}_{2}(\mathrm{OH})^{3-} \%$ & 0.46 & 15.51 & 0.02 & 0.02 \\
\hline & $\mathrm{UO}_{2}(\mathrm{OH})_{2(\mathrm{aq})} \%$ & 0.19 & 0.26 & 0.01 & 0.07 \\
\hline & $\mathrm{Ca}_{2} \mathrm{UO}_{2}\left(\mathrm{CO}_{3}\right)_{3(\mathrm{aq})} \%$ & 60.7 & 68.97 & 81.63 & 85.58 \\
\hline & $\mathrm{CaUO}_{2}\left(\mathrm{CO}_{3}\right)_{3}^{2-} \%$ & 37.28 & 14.98 & 18.08 & 13.41 \\
\hline & $\mathrm{UO}_{2}\left(\mathrm{CO}_{3}\right)_{2}^{2-} \%$ & 0.76 & 0.02 & 0.12 & 0.52 \\
\hline & $\mathrm{UO}_{2}\left(\mathrm{CO}_{3}\right)_{3}^{4-} \%$ & 0.51 & 0.13 & 0.15 & 0.06 \\
\hline
\end{tabular}

Table 3

- $\mathrm{pH}$, conductivity, total and soluble U concentrations and labile fraction determined by DGT (Chelex 100, DE81 and P81) for in situ and in lab deployments.

\begin{tabular}{|c|c|c|c|c|c|c|c|c|}
\hline & \multicolumn{2}{|l|}{014} & \multicolumn{2}{|l|}{041} & \multicolumn{2}{|l|}{$022 \mathrm{E}$} & \multicolumn{2}{|l|}{ 025E } \\
\hline & in situ & in lab & in situ & in lab & in situ & in lab & in situ & in lab \\
\hline $\mathrm{pH}$ & $8,5 \pm 0,5$ & $7,5 \pm 0,4$ & $9,8 \pm 0,1$ & $8,2 \pm 0,1$ & $8,3 \pm 0,2$ & $7,6 \pm 0,1$ & $7,7 \pm 0,5$ & $7,2 \pm 0,1$ \\
\hline Conductivity, $\mathrm{mS} \mathrm{cm} \mathrm{cm}^{-1}$ & $0,19 \pm 0,01$ & $0,18 \pm 0,01$ & $1,22 \pm 0,01$ & $1,05 \pm 0,06$ & $0,95 \pm 0,01$ & $0,88 \pm 0,01$ & - & $0,93 \pm 0,01$ \\
\hline Total $\mathrm{U} \mu \mathrm{gL}^{-1}$ & $3,73 \pm 0,24$ & $1,39 \pm 0,36$ & $14,15 \pm 0,37$ & $13,41 \pm 0,31$ & $3,14 \pm 0,61$ & $2,09 \pm 0,24$ & $4,55 \pm 0,16$ & 3,5 \\
\hline Soluble $\mathrm{U} \mu \mathrm{gL}^{-1}$ & $2,87 \pm 0,17$ & 1,10 & $13,03 \pm 0,55$ & $12,50 \pm 1,24$ & $2,24 \pm 0,26$ & $2,17 \pm 0,71$ & $4,45 \pm 0,19$ & $3,44 \pm 0,35$ \\
\hline $\begin{array}{l}\text { DGT } \\
\text { Chelex100 [\%] }\end{array}$ & $147 \pm 44$ & $191 \pm 5$ & $107 \pm 6$ & $121 \pm 7$ & $130 \pm 10$ & $115 \pm 22$ & $123 \pm 1$ & $186 \pm 35$ \\
\hline $\begin{array}{l}\text { DGT } \\
\text { DE81 [\%] }\end{array}$ & $76 \pm 3$ & $180 \pm 17$ & $37 \pm 2$ & $34 \pm 2$ & $52 \pm 0,2$ & $52 \pm 14$ & $50 \pm 1$ & $102 \pm 13$ \\
\hline $\begin{array}{l}\text { DGT } \\
\text { P81[\%] }\end{array}$ & $6 \pm 2$ & $13 \pm 3$ & $5,6 \pm 0,3$ & $3 \pm 2$ & $19 \pm 2$ & $18 \pm 2$ & $10 \pm 3$ & $4 \pm 1$ \\
\hline
\end{tabular}


(determined by DGT) U concentrations as well as the $\mathrm{pH}$, temperature and conductivity observed in situ and in lab for all sites.

At every site, a depletion of the total (from 5.2 to 62.7\%) and soluble (from 3.1 to $61.6 \%$ ) U concentrations was observed in in lab deployment compared to in situ deployment. This effect was negligible in sample/site 041 (total: 14.15 to $13.41 \mu \mathrm{g} \mathrm{L}^{-1}$; soluble: 13.03 to $12.50 \mu \mathrm{g} \mathrm{L}^{-1}$ ). However, this effect was significant at sites 025-E (total: 4.55 to $3.50 \mu \mathrm{g} \mathrm{L}^{-1}$; soluble: 4.45 to $3.44 \mu \mathrm{g} \mathrm{L}^{-1}$ ) and 014 (total: 3.73 to $1.39 \mu \mathrm{g} \mathrm{L}^{-1}$; soluble: 2.87 to $1.10 \mu \mathrm{g} \mathrm{L}^{-1}$ ). For most samples, the proportion of depletion was the same in the total and soluble concentrations. However, at site 022-E, a decrease in total U was verified $\left(3.14-2.09 \mu \mathrm{g} \mathrm{L}^{-1}\right)$, while the soluble concentration was maintained $\left(2.24-2.17 \mu \mathrm{g} \mathrm{L}^{-1}\right)$. These alterations may be caused by adsorption of the analyte by the flasks during sampling and storage. A decrease in $\mathrm{pH}$ was also observed in the laboratory (from 0.5 to 1.6 ), possibly due to $\mathrm{CO}_{2}$ input in the deployment flask caused by agitation during in lab deployment. The variation of the conductivity was negligible.

All of the labile fractions measured by the Chelex-100 resin tend to be higher than the soluble concentration, possibly due to changes in the diffusion coefficients. It is difficult to estimate the diffusion coefficient for each species of $U$ at an exact $\mathrm{pH}$. Nevertheless, it can be noted that no alteration was observed in the labile fractions determined by Chelex-100 in situ and in lab at sites 022-E ( in situ $=2.91$ to in lab $=2.50 \mu \mathrm{g} \mathrm{L}^{-1}$ ) and 041 (in situ $=14.00$ to in $l a b=15.17$ ). These values represent $130 \pm 10 \%$ (in situ) to $115 \pm 22 \%$ (in lab) in 022-E and $107 \pm 6$ (in situ) to $121 \pm 7$ in 041 (in lab) of the soluble fraction. Therefore, for these sites, the labile fractions measured by Chelex-100 were similar for the in situ and in lab deployments. A divergent behaviour was observed for samples 014 and 025-E. The measurements performed in situ were different than those performed in lab. The labile $\mathrm{U}$ concentrations determined at sites 014 and 025-E were, respectively, 4.23 and $5.50 \mu \mathrm{g} \mathrm{L}^{-1}$ in situ and 2.10 and $6.52 \mu \mathrm{g} \mathrm{L}^{-1}$ in lab. These values represent (of the soluble fraction) $147 \pm 44 \%$ (in situ) to $191 \pm 5 \%$ (in lab) for 014 site and $123 \pm 1 \%$ (in situ) and $186 \pm 35 \%$ (in lab) for site 025.

Concerning the anionic labile species of $U$ determined by DE81, a minor variation of labile concentration was observed between in situ and in lab measurements at sites 022-E (in situ $=1.17$ to in $l a b=1.14 \mu \mathrm{g} \mathrm{L}^{-1}$ ) and 041 (in situ $=4.47$ to in lab $=4.24 \mu \mathrm{g} \mathrm{L}^{-1}$ ). When comparing in situ and in lab measurements, an alteration occurred with DE81 for sites 025-E and 014. The anionic labile U concentrations determined in situ and in lab were, respectively, 2.21 and $3.57 \mu \mathrm{g} \mathrm{L}^{-1}$ in site $025-\mathrm{E}$ and 1.98 and $2.20 \mu \mathrm{g} \mathrm{L}^{-1}$ in site 014 . For site $025-\mathrm{E}$, these values represent $50 \pm 1 \%$ of the soluble fraction for the in situ measurements and $102 \pm 13$ for the in lab measurements. For site 014 , the in situ measurements represent $76 \pm 3 \%$ of the soluble fraction and the in lab measurements represent $180 \pm 17 \%$ of the soluble fraction.

The concentrations of cationic labile $U$ determined by the P81 membrane were $0.42,0.44,0.73$ and $0.18 \mu \mathrm{g} \mathrm{L}^{-1}$ for in situ deployment at sites 022-E, 025-E, 041 and 014, respectively. The concentrations determined in the in lab deployment were lower than those measured in situ $\left(0.38,0.15,0.38\right.$ and $0.15 \mu \mathrm{g} \mathrm{L}^{-1}$, for sites 022-E, 025-E, 041 and 014, respectively).

\section{Conclusions}

The results obtained in initial laboratory tests indicated that DGT can be employed to perform U speciation in treated AMD by using Chelex 100 as well as DE81 and P81 as binding phases. Chelex-100 resin retained all labile $U$ species (for a period of up to $48 \mathrm{~h}$ ) in all samples. The DE81 membrane was effective for retaining negative species of $\mathrm{U}$; however, it was restricted to immersions of, at most, $8 \mathrm{~h}$ without saturation. Saturation possibly occurs due to the high $\mathrm{SO}_{4}^{-2}$ content in the water. The P81 membrane exhibited a lower efficiency for retaining $U$ species. For the investigated samples, the obtained speciation with MINTEQ software was relatively in accordance with the values obtained with DGT. When comparing in situ and laboratory measurements, differences in speciation and the total and soluble concentrations of $U$ species are observed. In situ deployment can take into account variations of $U$ species during the sampling time due to punctual discharges in DAM treatment and environmental changes. Laboratory deployment cannot take these variations into account during the deployments. Additionally, interconversions of $U$ species before deployment (during storage) do not effectively represent the $U$ species in the environment. Therefore, accurate measurements of the total soluble concentration and speciation of Uranium must be performed in situ.

\section{Acknowledgments}

The authors thank the Fundação de Amparo à Pesquisa do Estado de São Paulo (FAPESP) and Conselho Nacional de Desenvolvimento Científico e Tecnológico (CNPq) for their financial support. Additionally, they also thank the Industrias Nucleares do Brasil (INB) for providing logistical support.

\section{Appendix A. Supplementary data}

Supplementary data related to this article can be found at http:// dx.doi.org/10.1016/j.chemosphere.2016.11.082.

\section{References}

Al-Hashimi, A., 1996. Aspects of the permanent storage of uranium tailings. Water Air Soil Pollut 88 (1), 83-92.

Colaço, C.D., Yabuki, L.N.M., Rolisola, A.M., Menegário, A.M., Almeida, E., Suárez, C.A., Gao, Y., Corns, W.T., Filho, V.F.N., 2014. Determination of Mercury in river water by diffusive gradientes in thin films using P81 membrane as binding layer. Talanta 129, 417-421.

CONAMA (Conselho Nacional do Meio Ambiente) (2005) Rule 357 published in 17th Mar 2005 http://www.mma.gov.br/port/conama/res/res05/res35705.pdf.

Davison, W., Zhang, H., 1994. In situ speciation measurements of trace components in natural waters using thin films gel. Nature 367, 546-548.

Davison, W., Zhang, H., 2012. Progress in understanding the use of diffusive gradients in thin films (DGT) - back to basis. Environ. Chem. 9 (1), 1-13.

Drozdzak, J., Leemakers, M., Gao, Y., Phorommanvanh, V., Descostes, M., 2015. Evaluation and application of Diffusive Gradient in Thin Films (DGT) technique using Chelex-100, Metsorb and Diphonix binding phases in uranium mining environments. Anal. Chim. Acta 889, 71-81.

Drozdzak, J., Leermakers, M., Gao, Y., Elskens, M., Phorommavanh, V., Descostes, M., 2016. Uranium aqueous speciation in the vicinity of the former uranium mining sites using the diffusive gradient in thin films and ultrafiltration techniques. Anal. Chim. Acta 913, 94-103.

Environmental Protection Agency (EPA), 2015. Drinking Water Requirements for States and Public Water Systems: Radionuclides Rule. Washington DC. Available from: https://www.epa.gov/dwreginfo/radionuclides-rule.

Fernandes, H.M., Franklin, M.R., 2001. Assessment of acid rock drainage pollutants release in the uranium mining site of Poços de Caldas - Brazil. J. Environ. Radioact. 54 (1), 5-25.

Francis, A.J., 1990. Microbial dissolution and stabilization of toxic metals and radionuclides in mixed wastes. Experentia 46, 8.

Garmo, O.A., Rosyset, O., Steinnes, E., Flaten, T.P., 2003. Performance study of diffusive gradients in thin films for 55 elements. Anal. Chem. 75, 3573-3580.

Gregusova, M., Docekal, B., 2011. New resin gel for uranium determination by diffusive gradient in thin films. Anal. Chim. Acta 684, 142-146.

Hutchins, C.M., Panther, J.G., Teasdale, P.R., Wang, F., Stewart, R., Bennett, W.W., Zhao, H., 2012. Evaluation of a titanium-dioxide based DGT technique for measuring inorganic uranium species in fresh and marine waters. Talanta 97, $550-556$.

Johnson, D.B., Hallberg, K.B., 2005. Acid mine drainage remediation options: a review. Sci. Total Environ. 338 (1), 3-14

Li, W., Li, C., Zhao, J., Cornett, R.J., 2007. Diffusive gradient in thin films technique for uranium measurements in river water. Anal. Chim. Acta 592, 106-113.

Li, W., Zhao, J., Li, C., Kiser, S., Cornett, R.J., 2006. Speciation measurements of uranium in alkaline waters using diffusive gradients in thin films technique. Anal. Chim. Acta 575, 274-280. 
Oliveira, R.L.F., Pedrobom, J.H., Menegário, A.A., Domingos, R.N., Py Junior, D.A., Kiang, C.H., 2013. Determination of in situ speciation of manganese in treated acid mine drainage water bud using multiple diffusive gradients in thin films devices. Anal. Chim. Acta 799, 23-28.

Santos, E.A., Ladeira, A.C.Q., 2009. Leaching of uranium from the Osamu Utsumi mine wastes, INB Caldas, Minas Gerais. In: 2009 International Nuclear Atlantic Conference - INAC 2009, Associação Brasileira de Energia Nuclear. ISBN: 97885-99141-03-8.

Souza, A.M., Silveira, C.C., Pereira, R.M., 2013. Contribuição dos metais provenientes das pilhas de rejeito da minaOsamu Utsumi a drenagem do Complexo Alcalino de Poços de Caldas, Minas Gerais. Geochim. Bras. 27, 63-76.

Strosnider, W.H.J., Llanos López, F.S., Nairn, R.W., 2011. Acid mine drainage at Cerro Rico de Potosí I: unabated high-strenght discharges reflect a rive century legacy of mining. Environ. Earth Sci. 64, 899-910.

Turner, G.S.C., Mills, G.A., Burnett, J.L., Amos, S., Fones, G.R., 2015. Evaluation of diffusive gradient in thin-films using a Diphonix resin for monitoring dissolved uranium in natural waters. Anal. Chim. Acta 854, 78-85.

Turner, G.S.C., Mills, G.A., Bowes, M.J., Burnett, J.L., Amos, S., Fones, G.R., 2014. Evaluation of DGT as a long-term water quality monitoring tool in natural waters; uranium as a case of study. Environ. Sci. Process. Impacts 16 (3),
$355-614$

Turner, G.S.C., Mills, G.A., Teasdale, P.R., Burnett, J.L., Amos, S., Fones, G.R. 2012. Evaluation of DGT Technique for measuring inorganic uranium species in natural waters: interferences, deployment time and speciation. Anal. Chim. Acta 739, 37-46.

Vandenhove, H., Hurtgen, C., Payne, T.E., 2010. Uranium. In: Atwood, D.A. (Ed.), Radionuclides Environ, vol. 2010. John Wiley \& Sons, Ltd, 261e287.

Veiga, L.H., Koifman, S., Melo, V.P., Sachet, I., Amaral, E.C., 2003. Preliminary indoor radon risk assessment at the Poços de Caldas Plateau, MG - Brazil. J. Environ. Radioact. 70, 161-176.

World Health Organization (WHO), 2006. Guidelines for Drinking-water Quality: Incorporating First Addendum, vol. 1. Recommendations. - 3rd ed. Geneva.

Zhang, H., Davison, W., 1999. Diffusional characteristics of hydrogels used in DGT and DET techniques. Anal. Chim. Acta 398, 329-340.

Zhang, H., Davison, W., 1995. Performance characteristics of diffusion gradients in thin films for the in situ measurements of trace metal in aqueous solution. Anal. Chem. 67, 3391-3400.

Zhang, H., Davison, W., 2000. Direct in situ measurements of labile inorganic and organically bound metal species in synthetic solutions and natural waters using diffusive gradient in thin films. Anal. Chem. 72 (18), 4447-4457. 